\title{
PEMBANGKITAN LUCUTAN PIJAR KORONA NEGATIF PADA KONDISI ATMOSFER DAN PENGARUHNYA TERHADAP RESAPAN AIR PADA KAIN KATUN DAN POLIESTER GREY
}

\author{
NEGATIVE CORONA DISCHARGE GENERATION AT ATMOSPHERIC \\ CONDITION AND ITS WATER ADSORBTION EFFECT ON GREY COTTON \\ AND POLYESTER TEXTILE
}

\author{
Zaenul Muhlisin ${ }^{123}$, Dhyan Prastiwi ${ }^{23}$, Herli Darliawati ${ }^{23}$, Achmad Sjaifuddin $\mathrm{T}^{4}$, Fajar Arianto ${ }^{23}$, Asep \\ Yoyo Wardaya ${ }^{23}$, Sumariyah ${ }^{23}$, Muhammad Nur ${ }^{23}$ \\ ${ }^{1}$ Email : muhlisin@gmail.com \\ ${ }^{2}$ Laboratorium Fisika Radiasi dan Fisika Medik, Departemen Fisika Universitas Diponegoro, Jl. Prof. \\ Soedarto SH Tembalang Semarang \\ E-mail: fisika@undip.ac.id \\ ${ }^{3}$ Central for Plasma Research, Jl. Profesor H. Soedarto, SH FSM UNDIP, City, Tembalang, Kota Semarang, \\ Jawa Tengah 50275 \\ ${ }^{4}$ Balai Besar Tekstil, Jalan Jenderal Ahmad Yani No. 390 Bandung \\ E-mail: texirdti@bdg.centrin.net.id
}

Tanggal diterima: 12 Desember 2017, direvisi: 9 Januari 2018, disetujui terbit: 11 Januari 2018

\begin{abstract}
ABSTRAK
Pada penelitian ini akan diungkapkan tentang lucutan korona negatif pada kondisi atmosfer dan bagaimana pengaruhnya terhadap sifat resapan air di kain poliester grey. Tujuan dari penelitian ini adalah membandingkan pembangkitan lucutan pijar korona negatif dengan dua jenis elektroda yang berbeda geometri dan mengamati sifat serapan air pada kain poliester grey yang telah diiradiasi dengan lucutan ini. Pembangkitan lucutan korona negatif pada kondisi atmosfer ini dilakukan dengan menggunakan dua jenis geometri elektroda, yaitu elektroda titik-bidang dan elektroda garis-bidang. Elektroda titik maupun garis diperlakukan sebagai katoda dan elektroda bidang diperlakukan sebagai elektroda anoda. Pengukuran beda potensial dan arus menggunakan multimeter digital. Iradiasi kain dilakukan dengan menempatkan kain katun maupun poliester pada elektroda bidang. Uji tetes dilakukan untuk mendapatkan karakter serapan air terhadap kain yang telah diiradiasi. Lucutan yang dibangkitkan pada kondisi atmosfer akan meningkat arusnya ketika diberi penambahan tegangan. Karakteristik lucutan saat kain berada anoda sedikit berbeda bila dibandingkan tanpa adanya kain, namun pola lucutan masih relatif sama. Pada uji tetes menunjukkan bahwa lucutan korona negatif pada kain poliester maupun katun berpengaruh pada penurunan waktu serap. Selain itu, durasi iradiasi terhadap kain sangat berpengaruh terhadap penurunan waktu serap air di kain katun maupun poliester. Penurunan mencolok terlihat pada kain poliester grey dimana sebelumnya 16 detik menjadi kurang dari 2 detik.
\end{abstract}

Kata kunci: lucutan korona negatif, kondisi atmosfer, kain katun, kain poliester, titik bidang

\begin{abstract}
A research on the nature of negative corona discharge at atmospheric condition and how it affects water absorption in cotton and grey polyester fabric has been carried out. It is aimed at comparing generation of negative corona discharge from two electrodes of different geometries and observing water absorption in cotton and grey polyester fabric irradiated with this discharge. The two electrodes used were point-to-plane and line-to-plane electrodes. Both point and line electrodes served as cathodes while the plane electrode served as the anode. Differences in potential and current were measured using a digital multi-meter. Fabric irradiation was conducted by putting both cotton and polyester cloths on the plane electrode. A drop test was then performed to figure out water absorption character of the cloths. It was observed that discharge characteristic differs when cloths are put on the anode, compared to the discharge without those cloths on the anode. However, discharge pattern was still the same. It was also revealed from the drop test that negative corona discharge on both cotton and polyester cloths affects absorption time. The longer the irradiation is, the less time it takes for the cloths to absorb water. This is especially true for the grey polyester, which recorded a dwindling absorption time, from 16 to less than 2 seconds.
\end{abstract}


In particular, the adsorption time of the grey polyester is decreased significantly i.e. from 16 to less than 2 seconds for before and after irradiation respectively.

Keywords: negative corona discharge, atmospheric condition, cotton, polyester, point-to-plane, line-to-plane

\section{PENDAHULUAN}

Industri tekstil merupakan industri yang sarat dengan penggunaan air untuk proses seperti scouring, desizing, bleaching, dyeing, dan finishing. Hal ini tentu menghasilkan polusi limbah dan juga mengkonsumsi energi yang banyak.. ${ }^{1}$ Proses-proses ini digunakan untuk mendapatkan sifat-sifat khusus sehingga kain dapat digunakan oleh penggunanya dengan nyaman. ${ }^{2}$ Salah satu parameter yang dipenuhi agar kain dapat nyaman digunakan adalah kandungan kelembaban kain. ${ }^{3}$

Metode yang saat ini banyak diteliti dan dikembangkan untuk pemrosesan tesktil adalah dengan perlakuan lucutan plasma pada kondisi atmosfer. Lucutan plasma yang dipilih unutk iradiasi tekstil ini merupakan plasma dingin. Kemampuan lucutan plasma untuk mengubah sifat dari permukaan melalui modifikasi secara fisika maupun kimia tanpa memodifikasi karakteristik bagian bulk telah diakui. Selain itu, dengan memanfaatkan lucutan plasma ini proses diindustri tekstil dapat meminimalisir penggunaan air dikarenakan proses dengan iradiasi plasma ini merupakan proses yang kering. ${ }^{1}$

Di Indonesia penelitian mengenai plasma pada kain diawali oleh Kaelani pada tahun 2000 yakni dengan menggunakan pembangkit plasma tipe DBD (Dielectric Barrier Discharge). Dengan menggunakan metode ini didapatkan penurunan berat pada rayon viskosa, akrilik, kapas, rayon asetat, nilon dan poliester. GDP (Glow Discharge Plasma) yang dihasilkan dapat digunakan sebagai inisiator untuk grafting beberapa monomer hidrofilik maupun hidrofobik dengan kemampuan yang berbeda-beda. Dari penelitian tersebut dapat disimpulkan bahwa penggunaan plasma pada kain dapat mengurangi pencemaran dan efisiensi bahan bakar yang digunakan. ${ }^{4}$

Selain dengan menggunakan tipe DBD, perlakukan kain dengan iradasi plasma juga telah dilakukan dengan jenis lucutan plasma pijar korona positif. ${ }^{5}$ Pembangkitan plasma pijar korona positif ini menggunakan elektroda bergeometri titik-bidang dimana elektroda titik diperlakukan sebagai anoda. Hal ini menyebabkan partikel-partikel plasma bermuatan postif akan terdeposisi ke kain katun dan poliester yang diletakkan di katoda. Perubahan karakter kemampuan serap air di kedua kain terjadi, dimana semakin lama waktu iradiasi plasma akan meningkatkan kecepatan serap air. ${ }^{6}$

Selain tipe DBD dan plasma pijar korona positif, juga terdapat plasma lucutan pijar negatif yang belum diperlakukan ke kain. Plasma lucutan pijar negatif pada kondisi atmosfer berisikan elektron dan ion-ion negatif plasma seperti $\mathrm{CO}_{3}{ }^{-}$ dan $\mathrm{NO}_{3}{ }^{-7}{ }^{-7}$ Pada tulisan ini akan dipaparkan bagaimana pengaruh lucutan pijar korona negatif pada kondisi atmosfer terhadap kemampuan serap air kain poliester mapun katun grey.

\section{METODE}

Skema peralatan yang digunakan pada penelitian ini menggunakan ditunjukkan oleh Gambar 1. Geometri elektroda yang digunakan sebanyak dua macam, yaitu elektroda titik-bidang dan elektroda garis bidang. Sebagai elektroda aktif adalah titik dan garis. Untuk elektroda titik digunakan sebanyak 100 buah titik dengan jarak antar titik adalah $1,3 \mathrm{~cm}$. Dimensi yang digunakan adalah adalah bujur sangkar dengan masing masing sisi berjumlah 10 titik dan jumlah baris 10 . Sedangkan sebagai elektroda garis digunakan logam bulat memanjang dengan panjang $12 \mathrm{~cm}$ dan jarak antar garis adalah 1,3 cm. Elektroda garis dan titik ini diperlakukan sebagai katoda. Elektroda positif digunakan logam dalam bentuk bidang yang juga digunakan sebagai tempat kain katun maupun poliester yang sebagai sampel.

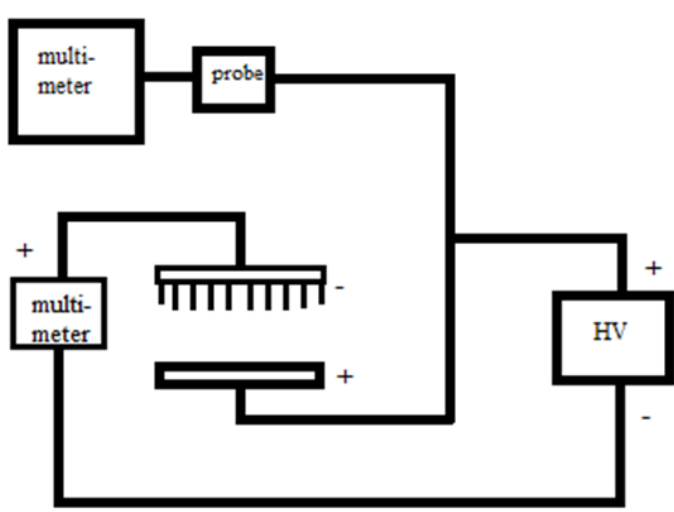

Gambar 1. Skema rangkaian peralatan penelitian 


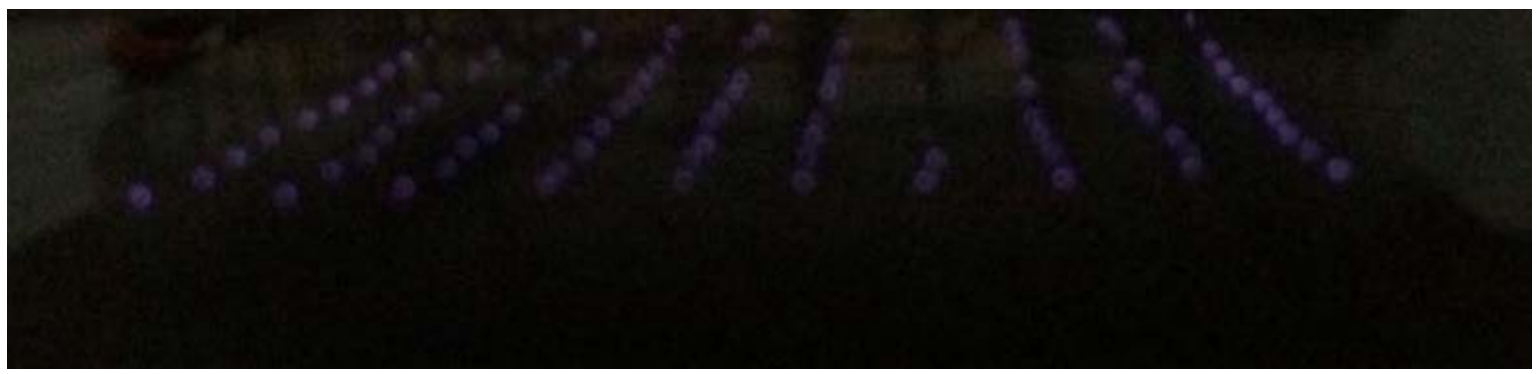

Gambar 2. Gambar lucutan korona negatif pada kondisi atmosfer dengan geometri elektroda multi titik bidang

Elektroda dihubungkan dengan pembangkit tegangan tinggi DC. Arus listrik diukur dengan menggunakan multimeter analog Multimeter SANWA tipe YX-380R yang dirangkaikan secara seri dari rangkaian. Pengukuran beda potensial dilakukan dengan menggunakan multimeter digital WENS 700S No. Seri 6945015 yang memiliki overload protection $1000 \mathrm{~V}$ (DC maupun AC), frekuensi $5 \mathrm{~Hz}$ - 1,3 GHz. Pada pengukuran beda potensial ini, arus listrik yang digunakan untuk pegukuran beda potensial diambil dari rangkaian yang dihubungkan terlebih dahulu dengan HV Probe dengan tipe EnG1010. Fungsi dari HV Probe adalah mengkonversi nilai $1000 \mathrm{~V}$ menjadi $1 \mathrm{~V}$.

Setelah peralatan dapat dirangkai sebagai mana ditunjukkan pada Gambar 1, kemudian dilakukan karakterisasi lucutan baik untuk elektroda bergeometri titik-bidang maupun garis bidang. Karakterisasi dilakukan dengan menaikkan pemberian beda potensial ke rangkaian. Pengamatan dilakukan baik pada nilai arus listrik yang ditunjukkan oleh multimeter SANWA tipe YX-380R maupun nilai beda potensial yang ditunjukan oleh multimeter digital WENS 700S No. Seri 6945015. Kegiatan karakterisasi ini dilakukan kembali untuk jarak antar elektroda yang berbeda. Karakterisasi lucutan kemudian dilakukan kembali dengan meletakkan kain di anoda. Langkah-langkah karakterisasi yang dilakukan adalah sama dengan karakterisasi tanpa kain.

Setelah karakterisasi lucutan telah dilakukan, kemudian melakukan iradiasi terhadap kain. Kain yang digunakan pada penelitian ini adalah kain katun $100 \%$ dan kain poliester. Iradiasi dilakukan pada lucutan korona yang merupakan salah satu bentuk dari plasma dingin. Selama iradiasi dilakukan baik beda potensial maupun arus rangkaian diusahakan konstan. Variasi yang dilakukan untuk hal ini adalah jangka waktu iradiasi dan jarak antar elektroda.

Setelah diiradiasi dengan plasma korona negatif, 24 jam kemudian pada kain sampel dilakukan uji tetes air untuk mendapatkan perilaku penyerapan air. Uji tetes ini dilakukan dengan meneteskan air sebanyak $1 \mathrm{~mL}$ ke kain sampel dengan jarak kain dengan mulut buret sejauh $1 \mathrm{~cm}$. Pengamatan dilakukan dengan mencatat waktu yang diperlukan air terserap di kain sampel.

\section{HASIL DAN PEMBAHASAN \\ Lucutan Korona Negatif}

Menurut klasifikasi lucutan gas, korona negatif dan suatu lucutan pijar mengacu ke tipe lucutan yang sama. Ketika lucutan pada daerah korona maka hanya diujung jarum yang nampak bercahaya putih. Di daerah antar elektroda dan elektroda bidang akan nampak gelap. Hal ini ditampilkan pada Gambar 2 yang memperlihatkan lucutan pada daerah pijar yang stabil. Akisev dkk. (2000) menunjukkan dengan foto negatif bahwa terdapat pijar plasma yang menyebar dan agak seragam. Hal ini dikarenakan struktur diskrit dari katoda multi titik. ${ }^{8}$

Gambar 3 menunjukkan karakteristik beda potensial - arus $(V-I)$ tereduksi terhadap tegangan $(V)$ elektroda dari lucutan plasma negatif dengan geometri elektroda multi titik-bidang. Jarak antara elektroda titik sebagai katoda dan elektroda bidang sebagai anoda pada lucutan tersebut adalah $3 \mathrm{~cm}$, $3,3 \mathrm{~cm}$ dan 3,6 cm. Dari ketiga grafik ini menunjukkan pola yang sama yaitu dimulai pada titik yang hampir sama dan kemudian grafik menanjak. Keadaan dari titik awal hingga sebelum mendaki merupakan arus elektron. Elektron muncul dari katoda yang merupakan elektroda aktif.

Grafik kemudian mendaki yang berturutturut dimulai dari elekroda berjarak $3 \mathrm{~cm}, 3,3 \mathrm{~cm}$ dan 3,6 cm. Pola grafik yang ditunjukkan gambar tersebut merupakan lucutan korona negatif. Semakin jauh jarak elektroda multi titik dan bidang grafik tampak semakin landai. Hal ini menunjukkan bahwa mobilitas partikel bermuatan negatif juga semakin kecil. sebagaimana yang dilakukan Susan dengan elektroda multi titik - bidang dengan lucutan korona positif. ${ }^{6}$ Partikel-partikel bermuatan 
negatif yang terbentuk pada lucutan kondisi atmosfer $\mathrm{O}_{2}^{-}, \mathrm{CO}_{3}{ }^{-}$dan $\mathrm{NO}_{3}{ }^{-7}$.

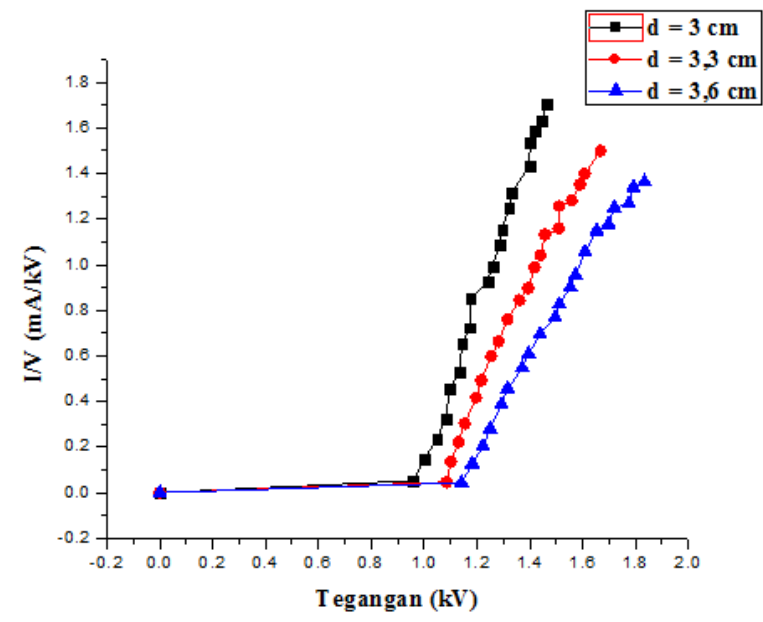

Gambar 3. Karakteristik V-I tereduksi terhadap tegangan dari lucutan korona negatif dengan elektroda multi titik-bidang dan jarak antar elektroda bervariasi

Gambar 4 menampilkan karakteristik V-I tereduksi tahadap tegangan dari lucutan plasma lucutan pijar korona baik dengan adanya sampel kain maupun yang tanpa adanya sampel kain. Sampel kain yang digunakan adalah kain poliester yang diletakkan di elektroda bidang (anoda) dengan jarak elektroda multi titik dan bidang adalah $3 \mathrm{~cm}$, 3,3 cm, dan 3,6 cm. Dari gambar tersebut nampak terjadinya perubahan pola lucutan. Keberadaan kain poliester di anoda justru membuat lucutan korona lebih mudah terbentuk. Hal ini berbeda dengan yang dilakukan Susan (2017) dimana keberadaan kain poliester di elektroda bidang justru akan sedikit menurunkan arus lucutan korona positif. ${ }^{6}$

Sebagaimana lucutan korona positif ${ }^{6}$, lucutan korona negatif juga memberikan perubahan karakter serapan air dari kain poliester sebagaimana ditampilkan oleh Gambar 5. Untuk lima variasi jarak antar elektroda menunjukkan bahwa semakin lama waktu spesies plasma korona negatif akan semakin mempersingkat waktu serap air di kain poliester tersebut. Bahkan untuk durasi waktu perlakuan 5 menit, pada jarak antar elektroda 1,8 cm sudah terjadi penurunan waktu serap air dari sekitar 17 detik menjadi kurang dari 4 detik. Pada jarak elektroda 2,1 cm, iradiasi lucutan korona negatif mampu menurunkan waktu serap air dari kain polister menjadi sekitar 1 detik. Penurunan waktu serap ini diakibatkan adanya tumbukantumbukan spesies-spesies plasma korona negatif ke kain poliester. Hal ini yang akan memberikan goresan ke kain yang akan meningkatkan adesifitas air ke kain poliester. ${ }^{1}$ Karakter yang demikian juga ditemui pada iradiasi lucutan korona positif ke kain polister. $^{6}$

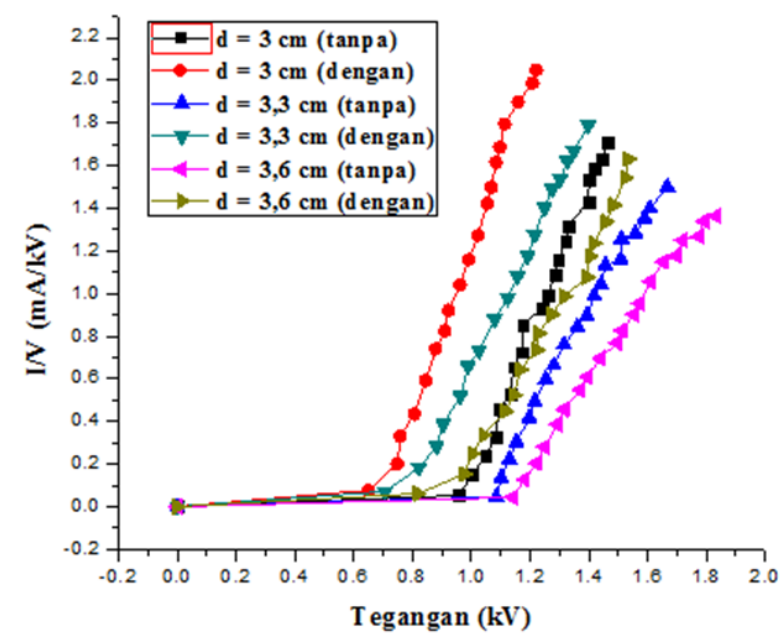

Gambar 4. Karakteristik V-I tereduksi dari lucutan korona negatif dengan kain poliester grey di anoda dan dilakukan variasi jarak.

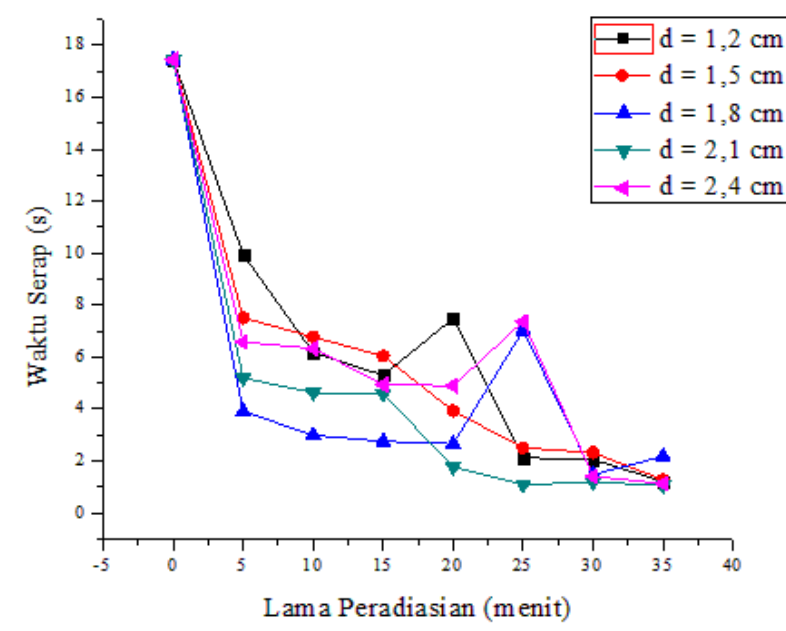

Gambar 5. Hasil uji tetes cairan sampel kain poliester grey dengan variasi jarak elektroda.

Selain elektroda multi titik sebagai elektroda aktif, jenis elektroda multi garis - bidang juga dapat digunakan untuk membangkitkan lucutan plasma pada kondisi atmosfer. Gambar 6 menunjukkan grafik karakteristik V-I tereduksi terhadap V dari lucutan korona negatif pada konfigurasi elektroda garis-bidang dengan jarak antar elektroda $3,3 \mathrm{~cm}$, 3,6, cm, dan 3,9 cm. Grafik lucutan yang terbentuk terpisah menjadi dua bagian, yaitu bagian dimana tegangan elektroda sebelum mencapai $7 \mathrm{kV}$ dan setelah $7 \mathrm{kV}$. Lucutan yang terbentuk sebelum 
tegangan mencapai $7 \mathrm{kV}$ adalah lucutan Townsend dan lucutan korona negatif baru muncul setelah beda potensial yang diberikan ke elektroda melewati $7 \mathrm{kV}$. Hal ini analog dengan hasil yang didapat Susan (2016) dimana untuk lucutan korona positif kondisi atmosfer muncul lucutan Townsend sebelum kemudian menjadi lucutan korona saat beda potensial yang diberikan ke elektroda semakin ditingkatkan. $^{5}$

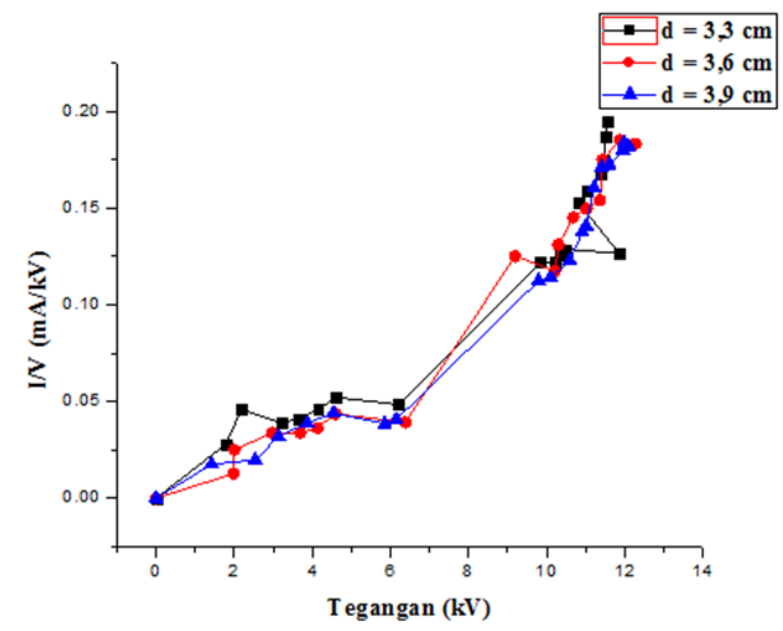

Gambar 6. Karakteristik V-I tereduksi dari lucutan korona negatif pada konfigurasi elektroda garis-bidang dengan variasi jarak antar elektroda.

Dengan dimensi elektroda aktif yang sama namun geometri elektroda beda, arus lucutan dari geometri garis bidang sangat rendah bila dibandingkan dengan lucutan yang dibangkitkan dengan elektroda muti titik-bidang. Hal ini dikarenakan arus lucutan terdistribusi secara kontinyu dari garis ke elekroda bidang. Selain itu, perubahan jarak elektroda tidak memberikan pengaruh yang berarti pada pola lucutan yang dihasilkan dari geometri ini.

Penyisipan kain katun grey yang diletakkan di elekroda bidang (anoda) tidak memberikan pengaruh terhadap pola lucutan yang secara berarti. Grafik lucutan baik dengan ataupun tanpa sampel kain katun grey tampak berhimpit. Tampilan grafik pola lucutan tanpa dan dengan kain katun grey dapat dilihat di Gambar 7.

Gambar 8 menampilkan karakteristik V-I tereduksi terhadap tegangan lucutan korona negatif pada konfigurasi elektroda garis bidang dengan kain katun grey di anoda dan dilakukan pada jarak antara elektroda $3,3 \mathrm{~cm}, 3,6 \mathrm{~cm}$ dan $3,9 \mathrm{~cm}$. Sebaran data nampak memberikan tanpilan pola lucutan korona negatif yang lebih baik dibandingkan dengan tanpa adanya kain (Gambar 6). Namun grafik untuk masing-masing jarak elektroda tetap terlihat saling berhimpit dan bahkan saling bertumpukan.

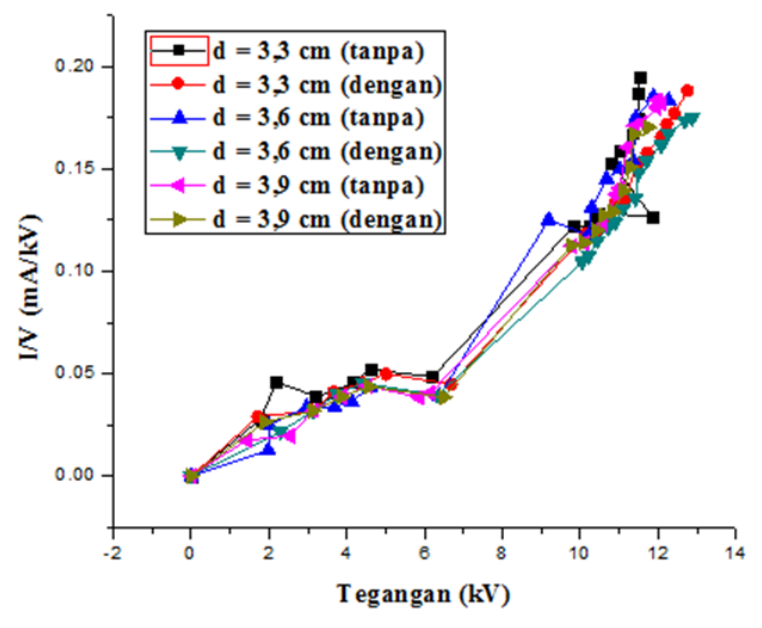

Gambar 7. Karakteristik arus fungsi tegangan lucutan korona negatif pada jarak 3,3 $\mathrm{cm}, 3,6 \mathrm{~cm}$ dan 4,5, cm dengan konfigurasi elektroda garis bidang baik, tanpa kain maupun dengan kain katun grey

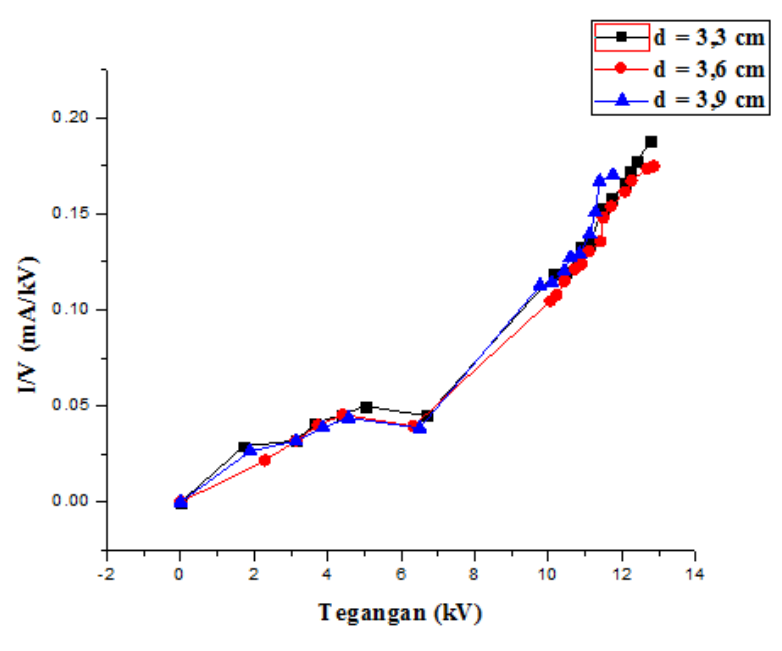

Gambar 8. Karakteristik V-I tereduksi terhadap tegangan lucutan korona negatif pada konfigurasi elektroda garis bidang dengan kain katun grey di anoda dan dilakukan variasi jarak antara elektroda

Perlakuan iradiasi lucutan pijar korona negatif terhadap kain katun grey mengubah karakteristik serapan air. Semakin jangka waktu perlakuan iradiasi penyerapan air semakin cepat 
pula. Hal ini ditunjukkan pada Gambar 9 dimana kain katun grey tanpa perlakuan iradiasi memerlukan waktu serap air lebih dari 6 detik dan terus menyingkat waktu serapan air hingga hampir 2 detik untuk perlakuan iradiasi 30 menit.

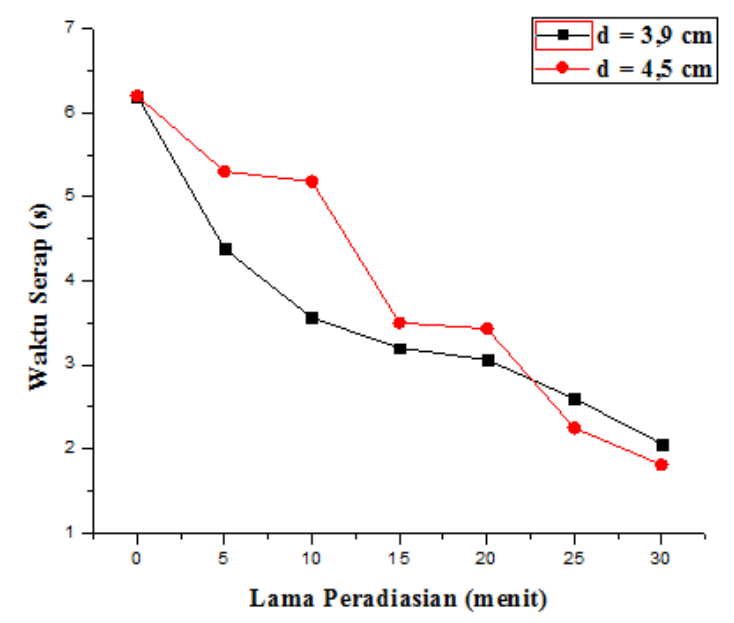

Gambar 9. Karakteristik waktu resapan air terhadap durasi iradiasi korona negatif pada jarak 3,9 cm dan 4,5, cm dengan konfigurasi elektroda garis bidang pada kain katun grey.

\section{KESIMPULAN}

Berdasarkan dari kajian di atas maka dapat ditarik kesimpulan bahwa lucutan plasma korona negatif pada kondisi atmosfer memiliki karakteristik sebagai berikut

- Pola pembangkitan lucutan negatif baik dengan elektroda bergeometri multi titik - bidang atapun multi garis - bidang diawali dengan lucutan Townsend sebelum lucutan korona terjadi.

- Keberadaan kain poliester grey di anoda mempercepat terjadinya lucutan korona negatif pada geometri multi titik - bidang.

- Keberadaan kain katun grey di anoda pada geometri multi garis - bidang akan memperlambat terjadinya lucutan korona negatif.

- Lucutan korona negatif berdampak pada penurunan waktu serap air baik untuk kain poliester grey maupun katun grey dimana semakin lama waktu iradiasi akan menurunkan durasi serap air di kain.

\section{UCAPAN TERIMA KASIH}

Penulis sangat berterimakasih atas bantuan pendanaan dari DIPA Fakultas Sains dan Matematika Universitas Diponegoro untuk pelaksanaan penelitian ini.
Untuk itu penulis mengucapkan terimakasih atas hal ini. Selain itu, penulis juga mengucapkan terima kasih terhadap Dr. Muhammad Widodo atas saran dan masukannya, dan kepada Ari Bawono untuk kesigapannya dalam penanganan instrumen yang digunakan selama penelitian.

\section{PUSTAKA}

1. Marcandalli, B. \& Riccardi, C., Plasma Treatments of Fibres and Textiles in Plasma Technology for Textile, Woodhead Publishing Limited, Cambridge, England, (2007).

2. Moertinah, S.,. Peluang-Peluang Produksi Bersih Pada Industri Tekstil Finishing Bleaching (Studi Kasus Pabrik Tekstil Finishing Bleaching Pt. Damaitex Semarang). TESIS. UNDIP (2008).

3. Kan, C. W., \& Lam, Y.L.. Low Stress Mechanical Properties Of Plasma-Treated Cotton Fabric Sunjected to Zinc Oxide- AntiMicrobial Treatment. Materials. 6, 314-333 (2013).

4. Kailani, Z., Pemanfaatan Energi Plasma Dalam Proses Tekstil Untuk Memperbaiki Sifat-Sifat Kain. Prosiding Seminar Nasional Sains dan Teknik Nuklir. Batan, Yogyakarta. (2005).

5. Susan, A.I., Sjaifudin, A.,Widodo M., \& Nur, M., Kajian Kelistrikan Plasma Pijar Korona Menggunakan Elektroda Multi Titik Bidang Dalam Perlakuan Tekstil. Arena Tekstil 31(1), 11-16, (2016).

6. Susan A.I., Widodo, M., \& Nur, M., Corona Glow Discharge Plasma Treatment for Hidrophycility Improvement of Polyester and Cotton Fabrics, IOP Conference Series : Material Science and Engineering 214, IOP Publishing 012031 doi:10.1088/1757899X/214/1/012031, (2017).

7. Skalny, J.D., Mikoviny, T., Matejcik, S., \& Mason, N.J., An Analysis of Mass Spectroscopic Study of Negative Ions Extracted from Negative Corona Discharge in Air, International Journal of Mass Spectrometry 233317 - 324. (2004).

8. Akishev, Y.S., Grushin, M.E., Kochetov, I.V., Napartovich, A.P., \& Pan’kin, M.V., Trushkin, N.I., Tansition of Multipin Negative Corona in Atmospheric Air to a Glow Discharge, Plasma Physics Report 26 (2). (2000). 